\title{
La derivación del derecho positivo desde el derecho natural en Tomás de Aquino. Un estudio a partir de Summa Theologiae y Sententia Libri Ethicorum $^{1}$
}

\author{
Sebastián Contreras Aguirre \\ UNIVERSIDAD DE LOS ANDES (CHILE) \\ sca@uandes.cl
}

1. Planteamiento. La derivación del derecho positivo desde el deRECHO NATURAL

Pese a que Santo Tomás haya señalado alguna vez que si los hombres fuesen justos no habría necesidad alguna de la ley², nos parece que incluso en una hipotética sociedad de santos se haría precisa la intervención del poder humano en orden a la regulación del bien social ${ }^{3}$. Esto por la máxima generalidad de los preceptos naturales, que no logran hacerse cargo de todas las circunstancias en las que se desarrollan los actos humanos, y que solo se nos presentan como criterios de orientación en la búsqueda de lo justo en el caso concreto.

Por supuesto que en una sociedad como la que describe el Aquinate en sus comentarios a San Pablo no serían necesarias las leyes contra el asesinato, la violación, el robo y otros actos moralmente incorrectos. "Pero sí serían pertinentes la gran mayoría de las leyes por las que las personas

\footnotetext{
Este trabajo forma parte de una investigación más amplia patrocinada por Fondecyt (proyecto de postdoctorado 3140035).

2 Cf. Tomás de Aquino, Super Epistolam Pauli Primam ad Timothaeum, 1, 3.

3 En este sentido, escribe Robert P. George: "la verdad es que la ley sería necesaria para coordinar el comportamiento de los miembros de la comunidad en la búsqueda del bien común, aun en una sociedad de ángeles. Por supuesto, en semejante sociedad, las sanciones legales (la amenaza de castigo por quebrantar la ley) serían innecesarias, pero las leyes, en sí mismas, todavía serían necesarias”. R. GEORGE, "Derecho natural y derecho positivo", Persona y Derecho, 39 (1998), 229-230.
} 
ven gobernadas sus vidas diarias como ciudadanos (particularmente en las complejas sociedades modernas)" ${ }^{2}$. Así, Santo Tomás sostiene que la ley positiva es necesaria, en primer lugar, porque los seres humanos que actúan, algunas veces necesitan el miedo al castigo para desistir de hacer lo que la ley natural ya prohíbe (o para requerirles a actuar conforme a lo que prescribe) "como una cuestión de justicia básica, pero también porque las prescripciones de la autoridad son, con frecuencia, necesarias para coordinar la acción en orden al bien común"s.

De ahí que, en nuestra opinión, la mencionada idea de Santo Tomás no represente lo más granado de su pensamiento. Su doctrina madura se encuentra, nos parece, en la Summa Theologiae, que es donde el maestro de Aquino defiende como necesario este proceso constructivo de las normas que se ha denominado concretización o simple determinación ${ }^{6}$, y en virtud del cual lo que decide la autoridad, "dejando a salvo el derecho natural, se convertirá en justo y adquirirá valor ético"7.

En cuanto a la determinación, escribe Santo Tomás que junto a los preceptos del derecho natural, a los que, en ocasiones, llama reglas de la ley moral $^{8}$ o de lo justo absoluto 9 , hay otros preceptos que no toman su fuerza obligatoria de la razón natural, "porque esos preceptos no implican un concepto absoluto de cosa debida o indebida" ${ }^{10}$. De esta manera, su fuerza obligatoria les viene, no directamente de lo justo por naturale$\mathrm{za}$, sino de la misma autoridad divina o humana que los determina como derecho vigente ${ }^{11}$.

4 R. George, "Kelsen y Santo Tomás sobre «la doctrina de la ley natural»", Persona y Derecho, 42 (2000), 82.

5 R. George, Kelsen y Santo Tomás sobre "la doctrina de la ley natural», 82.

6 Cf. J. Finnis, "On The Critical Legal Studies Movement”, en J. EekelaAr (ed.), Oxford Essays in Jurisprudence. Third Series (Oxford University Press, Oxford, 1987), 145-146.

7 F. Olgiati, El concepto de juridicidad en Santo Tomás de Aquino (Eunsa, Pamplona, 1977), 262.

8 Cf. Tomás de Aquino, Super Epistolam Pauli ad Philippenses, n. 119.

9 Cf. Tomás de Aquino, In Politicorum, I, lect. 4, n. 47.

10 Tomás de Aquino, Summa Theologiae, I-II, q. 104, a. 1.

11 Esta misma distinción se repite, mutatis mutandis, en el Comentario al Libro de los Salmos, donde Santo Tomás distingue entre preceptos que suponen una regla divina "a la que estamos obligados a seguir, y así cae bajo el deber aquello sin lo cual el 
Si estas determinaciones están hechas por institución divina en materias que miran a Dios, se llaman preceptos ceremoniales. Si están hechas por institución divina, pero en cosas que miran a las relaciones de unos hombres con otros, se llaman preceptos judiciales ${ }^{12}$. Si, en cambio, están hechas por institución humana, y respecto de aquellas materias que dicen relación directa con el logro del bienestar político de una comunidad particular, se llaman preceptos de derecho civil o de derecho positivo estricto. Es a este grupo de normas al que dedicaremos la mayor parte de nuestro trabajo, porque la determinatio que se aplica a las normas del derecho civil parece ser el sentido focal de las determinationes en el pensamiento de Santo Tomás. Así, cuando el de Aquino trata de los preceptos ceremoniales y judiciales de la Ley Antigua, da por supuesto todo lo expresado anteriormente a propósito del derecho positivo o simplemente legal.

Entonces, junto a las normas que se derivan de los principios comunes de la ley natural por vía de conclusión, "hay otras normas que se derivan por vía de determinación. Y así, la ley natural establece que el que peca sea castigado, pero que se le castigue con tal o cual pena es ya una determinación añadida a la ley natural"13. De acuerdo con esto, que los ladrones sean castigados es algo exigido por la propia justicia natural, pero la forma precisa de penalidad ha de ser puesta por la ley humana ${ }^{14}$. Por esto concluye Santo Tomás que, si bien es cierto que la ley natural dicta que la pena se debe aplicar en relación a la culpa, la determinación de la pena según las condiciones de la persona y la concreta magnitud de la culpa corresponde al derecho positivo ${ }^{15}$.

Lo anterior explica por qué la norma positiva o civil no dice no se debe matar, sino que especifica los distintos tipos de homicidio sin detener-

orden de la razón no puede ser mantenido", y preceptos dados por la autoridad de los hombres. Cf. Tomás de Aquino, In Psalmos, 18, 5.

12 Cf. Tomás de Aquino, Summa Theologiae, I-II, q. 104, a. 1.

13 Tomás de Aquino, Summa Theologiae, I-II, q. 95, a. 2. En otros pasajes del Corpus Thomisticum se encuentra esta misma referencia a la determinación de las penas: In Ethicorum, V, lect. 12, n. 1023; Summa Theologiae, II-II, q. 85, a. 1, ad 1; Quodlibetales, 2, 8; In Sententiraum, IV, d. 26, q. 2, a. 2.

14 Cf. J. Finnis, “The Truth in Legal Positivism”, en su Philosophy of Law (Oxford University Press, Oxford, 2011), 172 ss.

15 Cf. Tomás de Aquino, In Sententiarum, IV, d. 36, q. 1, a. 1. 
se en consideraciones acerca de la bondad o maldad del acto de matar (cuestión que ya está resuelta por la justicia natural). Por esta razón, más que obtenerse como una deducción desde la ley natural, lo justo positivo contiene los preceptos naturales, tal y como toda proposición verdadera contiene, de algún modo, los primeros principios del pensamiento especulativo ${ }^{16}$.

Una vez llevada a cabo la determinación, la norma resultante no es ya un derecho natural puro ni tampoco una norma natural positivada (que sería el derecho de gentes), sino solo lo justo instituido arbitrariamente $^{17}$, un conjunto de normas-complemento que surgen a partir de la libre inventiva del legislador humano ${ }^{18}$, aunque dentro de los márgenes de la razonabilidad práctica. Tales normas no reciben, al menos no directamente, su fuerza obligatoria desde los primeros principios del orden práctico, sino solo de su autor, el legislador humano, que ejerce un verdadero poder normativo, aunque limitado ${ }^{19}$ : crea en el sentido fuerte de la palabra, "nuevos preceptos, a condición [...] de no estatuir contra las exigencias de la ley natural" 20 , que son el principal límite al ejercicio de su potestad.

De esta forma, la norma positiva no puede abrogar los mandatos y prohibiciones naturales, esto es, "no puede destruir la obligatoriedad de la norma jurídica natural que prescribe o prohíbe una conducta" ${ }^{21}$. Tal obligatoriedad no es extrínseca a la norma de justicia natural, sino un elemento constitutivo suyo, en tanto que dicha condición "se asienta en un deber de justicia fundado en la naturaleza humana"22. Por esta razón, una norma positiva verdadera no podrá estar en conflicto con la norma

16 Cf. J. Martínez, Reconsideraciones sobre el pensamiento político de Santo Tomás de Aquino (Editorial de la Facultad de Filosofía y Letras de la Universidad Nacional de Cuyo, Mendoza, 1999), 208.

17 Cf. M. Villey, Compendio de filosofía del derecho. Los medios del derecho (Eunsa, Pamplona, 1979), 235.

18 Cf. D. Herrera, La noción de derecho en Villey y Kalinowski (Educa, Buenos Aires, 2005), 210.

19 Cf. G. Kalinowski, Concepto, fundamento y concreción del derecho (Abeledo-Perrot, Buenos Aires, 1982), 69.

20 G. Kalinowski, Concepto, fundamento y concreción del derecho, 69.

21 J. Hervada, Introducción crítica al derecho natural (Eunsa, Pamplona, $2011^{11}$ ), 173.

22 J. HervadA, Introducción crítica al derecho natural, 173. 
natural, aunque sí podrá, por ejemplo, disponer la restricción de algunos derechos en razón del bien común, como cuando se limitan derechos individuales que, por la misma razón natural en que se fundan, están subordinados a ese bien común.

De acuerdo con lo anterior, y por razones de necesidad pública, puede limitarse el uso de ciertos bienes o el ejercicio de ciertas libertades. Esto no supone una tensión entre lo justo legal y lo justo natural, sencillamente porque es de derecho natural el cumplimiento de las determinaciones de la autoridad y el logro del bien común en unas circunstancias particulares de lugar y tiempo (donde tales determinaciones son las más adecuadas). En estos casos, y otros semejantes, sea tolerando actos malos por su naturaleza, sea sujetando a solemnidades la validez de los actos jurídicos, sea limitando en materias de su competencia la libertad o el dominio individual, con tal que obre con razón proporcionada y en vistas del bien común, la ley positiva no atenta contra lo justo natural ${ }^{23}$; y esto porque lo propio de ese tipo de normas es dar, aquí y ahora, una aplicación prudencial a los preceptos de la recta razón.

Por lo tanto, además de ser aplicable cuando, de hecho, se conforma con lo justo natural, el derecho positivo es también aplicable cuando es indiferente ante el derecho por naturaleza que una cosa sea hecha de uno $\mathrm{u}$ otro $\operatorname{modo}^{24}$, o incluso cuando el legislador, por la consideración de unas muy particulares circunstancias, decide la restricción de ciertos derechos en razón de la seguridad pública. Ahora, independientemente del caso, lo que importa en cuanto al problema de la determinación, es que una vez que la ley ha sido establecida, aquello que decide la autoridad deja de ser indiferente, porque entonces "observar esto es justo, y desecharlo es injusto" 25 . "Por esto dice el Filósofo [...] que lo justo legal es lo que, en principio, nada exige que sea así o de otro modo; mas una vez establecido, sí debe ser de un modo y no de otro" ${ }^{26}$. Sin perjuicio de ello, si algo connota una oposición efectiva contra la ley natural, "no puede hacerse justo por la voluntad de los hombres, como si se estableciera que

23 Cf. R. Fernández Concha, Filosofía del derecho o derecho natural (Tipografía Católica, Madrid, 1887-1888), 171.

24 Cf. Tomás de Aquino, Summa Theologiae, II-II, q. 60, a. 5.

25 Tomás de Aquino, In Ethicorum, V, lect. 12, n. 1020.

26 Tomás de Aquino, Summa Theologiae, II-II, q. 57, a. 2. 
es lícito robar o adulterar. Y por eso exclama Isaías: jAy de aquellos que redactan leyes inicuas! ${ }^{27}$.

Santo Tomás explica la naturaleza de la derivatio per modum determinationis apelando solamente al caso de la especificación de las penas y a la analogía entre la tarea del legislador y la actividad del artesano ${ }^{28}$. La principal referencia a esta comparación se encuentra en la q. 95, a. 2 de la I-II, pero esta idea ya está presente en los comentarios al Liber Sententiarum ${ }^{29}$, que son la primera gran obra de Santo Tomás ${ }^{30}$. Si bien el empleo de esta comparación como medio para explicar la naturaleza de la determinación es insuficiente, no obstante ello parece interesante, porque, en efecto, no existe una única manera de diseñar una casa ${ }^{31}$. Muchos diseños diferentes son, sin ninguna duda, bastante razonables. Y es más: mientras que ciertas características del proyecto serán determinadas por las necesidades de la persona o la familia que ocupará la vivienda, otras serán, simplemente, materia de estilo y gustos ${ }^{32}$.

27 Tomás de Aquino, Summa Theologiae, II-II, q. 57, a. 2. Según esto, observa Santo Tomás que "antes que se instituyeran las leyes, en nada difería hacer esto o aquello. Pero una vez instituidas [...] las cosas cambiaron, porque desde entonces lo justo va a consistir en observarlas y lo injusto en pasarlas por alto, como en cierta ciudad fue instituido que el cautivo sea redimido pagando un cierto precio, y que se sacrificara una cabra pero no dos ovejas".

28 También se ha propuesto otra comparación para dar cuenta de esta proximidad entre la tarea legislativa y las obras del arte. Francesco Carnelutti ha indicado que las actividades de determinación del derecho son similares a la tarea de un anatomista que disecciona un cuerpo al hacer la autopsia: así como no se puede diseccionar sin preparar los bisturíes, tampoco se puede ejercer esta tarea de construcción de las normas positivas sin considerar los principios morales que subyacen a las reglas del derecho positivo o civil y las diversas circunstancias en las que el legislador lleva a cabo su tarea de determinación. Cf. F. Carnelutti, Discorsi in torno al diritto, (Cedam, Padua, 1961), 266 ss.

29 Cf. Tomás de Aquino, In Sententiarum, III, d. 37, q. 1, a. 3.

30 Cf. J. Torrell, Iniciación a Tomás de Aquino: su persona y su obra (Eunsa, Pamplona, 2002), 357.

31 Cf. J. García-Huidobro, "La recepción de la doctrina aristotélica sobre el derecho natural en el Comentario de la Ética a Nicómaco de Santo Tomás de Aquino”, Anuario Filosófico, 32/1 (1999), 238-239.

32 Cf. R. George, Entre el derecho y la moral (Aranzadi-Thomson, Navarra, 2009), 51-52. 
Es importante notar, en todo caso, que la analogía que hace Santo Tomás entre la tarea del legislador y la actividad del artesano no es arbitraria. En nuestra opinión, esta comparación representa un punto de contacto con una de sus principales intuiciones en materia política, en concreto, aquella que da inicio a sus comentarios al texto de la Política del Estagirita: ars imitatur naturam ${ }^{33}$. Así, aunque, prima facie, lo que es artificial se contrapone a lo que es natural, esto no quiere decir que no exista alguna vinculación entre lo que es por el arte y lo que es por la naturaleza. De hecho, en el ejercicio de su actividad constructiva, el artesano se sirve de instrumentos naturales que utiliza como patrón ${ }^{34}$, de tal manera que, escribe Santo Tomás, "tanto más perfecta es la obra del arte, cuanto más imita la natural”35.

Si nuestra lectura es correcta, lo que está intentando decir Santo Tomás es que, al igual que en las tareas productivas, donde el artesano sigue las realidades de la naturaleza como puntos de comparación, así también en la tarea de legislar, la autoridad política pone en práctica su actividad de creación del derecho a partir de unos principios naturales, los que considera como modelos de su arte. Esto se prueba, nos parece, por las propias palabras de Santo Tomás, cuando señala: "si la ley humana pudiera definir quiénes son los mejores por su mente, ordenaría sin duda que, conforme a lo natural, estos hombres fuertes fuesen los predominantes" 36 .

Nos parece que esta interpretación de la analogía entre las producciones y la actividad legislativa es adecuada, porque, como señala el de Aquino, "el arte puede remitirse a las cosas naturales y usarlas para perfeccionar su propia obra, pero no puede perfeccionar a la misma

33 Cf. Tomás de Aquino, In Politicorum, I, proemium. Por supuesto que el concepto de arte usado en este pasaje no equivale al empleado por Santo Tomás en sus comentarios a la Ética: arte significa acá, no un hábito o disposición del intelecto práctico, sino un principio general de todas las acciones humanas. Cf. Tomás DE Aquino, De Regno, 1, c. 2.

34 Cf. A. Vendemiati, San Tommaso e la legge naturale (Urbaniana University Press, Roma, 2011), 137.

35 Tomás de Aquino, De Regno, 1, c. 2. Sin embargo, escribe Santo Tomás que la naturaleza "solo dispone algunos principios y presta en cierto modo a los artífices el modelo para obrar". Tomás de Aquino, In Politicorum, I, proemium.

36 Tomás de Aquino, In Politicorum, I, lect. 4, n. 47 (énfasis añadido). 
naturaleza" ${ }^{37}$. Luego, el gobernante, cuando determina el derecho natural, no realiza una actividad constructiva ex nihilo, sino que procede a partir de unas verdades naturales que son el principio de su operación ${ }^{38}$. Estas verdades son simples ${ }^{39}$ y permiten que el legislador proceda de lo primero a lo posterior ${ }^{40}$, de principios de justicia absolutamente generales, y, por ello, insuficientes para regir la conducta de los hombres, a reglas de la acción más particulares, que consideran las distintas circunstancias en las que se llevan a cabo los actos humanos.

La tarea del legislador, en consecuencia, supone el paso de unos pocos principios naturales ${ }^{41}$, simples e imperfectos ${ }^{42}$, a unas reglas de justicia complejas y perfectas ${ }^{43}$, en una forma de arte que tiene como finalidad hacer más concretas aquellas verdades universales de la justicia natural. Solo así se explican las palabras de Santo Tomás en orden a señalar que "todo juicio de la razón práctica se funda en ciertos principios naturalmente conocidos" ${ }^{4}$.

Dicho esto, la comparación con la actividad del artesano se debe a que una idea general, como casa o puerta, tiene que concretarse en una casa o puerta en particular ${ }^{45}$, "con especificaciones que ciertamente se derivan de y están informadas por la idea general, pero que podrían haber sido

Tomás de Aquino, In Politicorum, I, proemium. De acuerdo con esto, concluye Santo Tomás: "por todo esto es evidente que la razón humana, frente a aquellas cosas que existen por naturaleza, solo es cognoscitiva, en cambio, frente a aquellas cosas que son a causa del arte, no solo es cognoscitiva, sino también productora. Por esto, es necesario que las ciencias humanas que se refieren a las cosas naturales sean especulativas, en cambio las que se refieren a las cosas que el hombre produce, sean prácticas, es decir, que procedan imitando a la naturaleza".

38 Y, en este sentido, "todo factor cultural, toda cosa hecha o constituida por el hombre depende, en su radical posibilidad de existir, de un factor natural. Toda actividad del hombre, toda posibilidad suya de hacer o tener algo depende de su propio ser, de las tendencias y capacidades a él inherentes y de los bienes que lo constituyen”. J. Hervada, Introducción crítica al derecho natural, 112.

39 Cf. Tomás de Aquino, In Politicorum, I, proemium.

Cf. Tomás de Aquino, In Physicorum, II, lect. 13, n. 174.

41 Cf. Tomás de Aquino, In Politicorum, I, proemium.

42 Cf. Tomás de Aquino, In Politicorum, I, proemium.

43 Cf. Tomás de Aquino, In Politicorum, I, proemium.

44 Tomás de Aquino, Summa Theologiae, I-II, q. 100, a. 1.

45 Cf. J. Finnis, Natural Law and Natural Rights (Clarendon Press, Oxford, 1989), 284. 
más o menos diferentes en muchos aspectos y dimensiones particulares [...] y que por lo tanto exigen del artista una multitud de elecciones" ${ }^{46}$. En este sentido, así como el artista, una vez fijado su propósito, no se queda en las cuestiones puramente especulativas que explican su tarea constructiva, sino que considera, sobre todo, las condiciones particulares de lugar y tiempo en donde se ha propuesto la ejecución de su obra, así también el legislador "no considera solo las leyes del hombre en cuanto hombre, sino que calcula los fines históricos y las más diversas contingencias, las que habrán de convertirse en la regla de su actividad constructiva de la norma jurídica" ${ }^{47}$. De ahí que a la derivación por determinación también se le conozca como derivación per modum factionis ${ }^{48}$.

Si esta analogía entre el proceder de la autoridad y la actividad del artesano es adecuada, ese mismo ámbito de libertad creativa que posee el artista ha de darse también en el surgimiento del derecho positivo o simplemente legal. Por eso es que, en opinión de Robert George,

al igual que el arquitecto, el legislador dispondrá en muchos ámbitos de su ejercicio de una considerable medida de libertad creativa [...] por medio de la cual creará diestramente planes concretos de regulación que apunten a la coordinación de la conducta en vistas del bienestar general de la comunidad, es decir, del bien común ${ }^{49}$. Y esto porque, al igual que en las artes, donde la idea común tan solo orienta la actividad del artesano sin especificarla en los detalles, la norma positiva está controlada pero no completamente determinada por lo justo natural ${ }^{50}$.

46 J. Finnis, Natural Law and Natural Rights, 284.

47 F. Olgiati, El concepto de juridicidad en Santo Tomás de Aquino, 262. En este sentido, señala Robert George: si bien el poder del Estado puede adoptar un gran número de soluciones, compatibles con la finalidad que está llamado a servir -el bien común social-, "esa libertad de ningún modo implica una independencia total de la ley positiva con respecto a la ley natural (igual que la libertad creadora del arquitecto no supone su completa independencia con respecto a los principios generales de la arquitectura, que deben ser observados si se desea que una casa sea estructuralmente correcta y por tanto adecuada para ser habitada; ni con respecto a los términos del acuerdo previo)". R. George, Kelsen y Santo Tomás sobre "la doctrina de la ley natural», 85.

48 Cf. G. Graneris, La filosofía del derecho a través de su historia y de sus problemas (Editorial Jurídica de Chile, Santiago, 1979), 146.

49 R. George, "Natural Law", Harvard Journal of Law \& Public Policy, 31 (2008), 189.

50 Cf. J. Finnis, Natural Law and Natural Rights, 284. 
Todo esto nos permite sostener que Santo Tomás está lejos de menospreciar el papel constructor de la prudencia en materia legislativa. El momento normativo de la prudencia regnativa no es una simple aplicación teoremática del derecho natural. Es una instancia creadora, que representa, sobre todo, una opción histórica de parte de la autoridad ${ }^{51}$. Solo así se entiende que el Aquinate haya insistido en que el ordenamiento de justicia emanado de las determinaciones no es una inventio, o hallazgo, sino una adinventio ${ }^{52}$, un aedificatum ${ }^{53}$, una constructio $^{54}$, en el sentido fuerte de los términos ${ }^{55}$.

Un ejemplo de esto lo vemos a propósito de la división de la propiedad: la comunidad de los bienes se atribuye al derecho natural, no porque este disponga que todas las cosas deban ser poseídas en común y que nada deba poseerse como propio, "sino porque la distinción de posesiones no es según el derecho natural, sino según la adiventio humana, lo cual pertenece al derecho positivo" 56 . De este modo, la propiedad de las posesiones no está contra el derecho natural, sino que es un desarrollo de este hecho por la razón humana, una aplicación o concreción de lo justo natural según las necesidades particulares de una sociedad política que aspira a la felicidad común.

En definitiva, las materias sobre las que recae la derivación por determinación no son sino aquellas que, de suyo, no requieren una decisión en algún sentido determinado, sino simplemente una decisión que

51 Cf. J. Hervada, Lecciones propedéuticas de filosofía del derecho (Eunsa, Pamplona, 2008), 606. Ahora bien, las determinaciones representan opciones históricas, porque ante el legislador se muestran una serie de posibilidades distintas e igualmente razonables para dar concreción y especificación a los principios naturales. Como se trata de posibilidades igualmente válidas, cuando la autoridad construye la norma positiva, elige uno de los tantos caminos posibles para realizar su tarea de determinación. Luego, escoge, decide, según las condiciones históricas de su comunidad, por tales o cuales salidas.

52 Cf. Tomás de Aquino, Summa Theologiae, I-II, q. 91, a. 3.

53 Cf. Tomás de Aquino, Summa Theologiae, I-II, q. 90, a. 1.

54 Cf. Tomás de Aquino, In Analytica Posteriora, I, lect. 14.

55 Cf. L. Lachance, Humanismo político. Individuo y Estado en Tomás de Aquino (Eunsa, Pamplona, 2001), 323.

56 Tomás de Aquino, Summa Theologiae, II-II, q. 66, a. 2. 
excluya otras posibles ${ }^{57}$. Por eso la determinatio se explica a partir del ámbito de lo indiferente, lo que no significa que la tarea creativa del legislador entrañe el ejercicio de una libertad absoluta. Esto quiere decir, más bien, que la actividad inventiva de la autoridad es libre, pero dentro de los márgenes de la razonabilidad práctica, y sin que ello contravenga lo dispuesto por la justicia natural ${ }^{58}$. De ahí que escriba Santo Tomás que las normas positivas prohíben únicamente "lo que puede ser ocasión de males, o prescriben algo que ordena hacia la virtud" 59 , porque, según su conformidad con la virtud, las leyes de la república serán rectas o injustas ${ }^{60}$.

\section{La determinación del derecho natural en Summa Theologiae}

Escribe Santo Tomás que una norma puede derivarse de la ley natural de dos maneras: o bien como una conclusión de sus principios más generales, como sucede en las normas del derecho de gentes; o bien como una determinación de aquello que en la ley natural permanece indeterminado o sin detalles, como en las reglas del derecho civil. El primer procedimiento es semejante al de las conclusiones demostrativas que en las ciencias se infieren de los principios; el segundo se asemeja a lo que sucede en las artes, donde las formas comunes reciben una determinación al ser aplicadas a realizaciones especiales ${ }^{61}$, tal como hemos indicado unas páginas más atrás.

Como ya nos hemos referido a la pertinencia de la comparación entre lo que sucede en las artes y la tarea legislativa, a continuación revisaremos el significado del apelativo derivadas que se aplica a las normas del derecho civil o positivo, y que Santo Tomás emplea en el texto de la q. 95 a. 2 de la I-II. Para esto debemos indicar, en primer lugar, que en la

57 Cf. J. Alvarado, La determinación del derecho en Santo Tomás (Pontificia Universidad Católica de Chile, tesis de licenciatura, Santiago, 1993), 14.

58 En este sentido, escribe Juan Carreras y Arañó: "como el hombre tiene obligación de conformar todas sus acciones particulares a los preceptos de la ley natural, es claro que la ley humana, hecha por y para hombres, se ha de hallar en armonía con aquella, para que no se convierta en elemento de perturbación”. J. CARRERAS y Arañó, Filosofía de la ley según Santo Tomás de Aquino (Reus, Madrid, 1919), 156.

59 Tomás de Aquino, In Sententiarum, IV, d. 15, q. 3, a. 1.

60 Cf. Tomás de Aquino, In Politicorum, II, lect. 13, n. 178.

61 Cf. Tomás de Aquino, Summa Theologiae, I-II, q. 95, a. 2. 
determinación no existe deducción alguna. La concreción de las normas de justicia natural es un problema de prudencia y no de geometría legal. Quizá por eso no sea tan sencillo hablar de una derivación de la ley positiva desde la ley natural en este caso, ya que la idea misma de derivación parece estar fuertemente cargada de un aspecto deductivo ${ }^{62}$.

Lo que pasa es que derivación significa acá, no derivación del contenido específico de la norma ${ }^{63}$ (como en el caso de la derivación por conclusión), sino derivación de la fuerza de obligar ${ }^{64}$. Los principios morales no establecen el contenido específico de las reglas de justicia legal; solo señalan el marco normativo dentro del cual el legislador puede disponer como obligatoria una conducta $\mathrm{X}$ en vez de $\mathrm{Y}$.

Esto es lo que explica que lo que pertenece a la determinación no sea de ley natural ${ }^{65}$, y que el tipo de conductas ordenadas de este modo sean obligatorias solo por la autoridad del gobernante. Tal es la interpretación del Cardenal Cayetano, Tomás de Vio, según el cual la obligación de obediencia del derecho humano no depende, inmediatamente, de los contenidos de la ley, sino del poder que tiene la república de establecer lo que es obligatorio para una ciudad determinada ${ }^{66}$.

Lo anterior se traduce en que toda ley civil toma su fuerza vinculante de su conformidad con el derecho natural, aunque la causa eficiente de esa norma sea directamente la voluntad de los hombres. En este sentido, los principios de la ley natural se hacen siempre presentes en la creación de las normas positivas, porque, como señala Finnis, esos principios de

62 Erradamente, a nuestro entender, autores como Francisco Carpintero llegan a declarar que en este pasaje de la Summa Santo Tomás enfatiza en el carácter deductivo de la creación del derecho. Nos parece que este es un juicio equivocado, y que representa una lectura inadecuada del texto del Aquinatense. Cf. F. CArpintero, "La «adaequatio hermeneutica» en Tomás de Aquino", Philosophica, 35 (2009), 117.

63 Hablamos de contenido específico, porque, de alguna manera, en la determinación sí existe una forma de derivación del contenido de la norma positiva, en la medida que las leyes humanas, o bien explicitan las prescripciones naturales, o bien disponen contenidos que no son contrarios al derecho natural.

64 Es por esto que la proposición de derecho natural puede ser, verdaderamente, principio de la derivación de las leyes positivas. En caso contrario, solo podría hablarse de una derivación conclusiva o deductiva desde los communissima.

65 Cf. M. Rhonheimer, Ley natural y razón práctica. Una visión tomista de la autonomía moral (Eunsa, Pamplona, 2000), 279.

66 Cf. Tomás de Vio (Cayetano), In Primam Secundae, q. 95, a. 2. 
justicia no solo justifican el ejercicio de la autoridad; sobre todo explican la fuerza obligatoria de las leyes del derecho humano ${ }^{67}$.

Se entiende, de esta forma, por qué Santo Tomás insiste en que la fuerza de la ley humana depende de su nivel de justicia, que es lo mismo que decir de su conformidad con la norma de la razón, que es la ley de la naturaleza ${ }^{68}$. Siendo esto así, lo que se deriva en el caso de la determinatio no son los contenidos de la norma positiva; lo que se deriva es la racionalidad y fuerza obligatoria de las reglas del derecho de ley.

Aunque el hecho de que se trate de preceptos derivados de la ley natural podría hacernos pensar que entre los principios universales de justicia y los preceptos del derecho civil existe un insoslayable encadenamiento lógico, lo cierto es que no existe un proceso deductivo que dé origen a las normas positivas o convencionales. Este proceso es prudencial, y, por lo tanto, dependiente de la contingencia y variabilidad de las circunstancias de la comunidad política. Es más, si esto fuera así, y las normas positivas fueran meras deducciones de la ley natural, el legislador debería estar buscando la ley recta, en el sentido de la norma que es la única correcta en todas las circunstancias, tal como un científico de mente laplaceana podría pensar que existe una única explicación determinada y completa para todo lo que ha acontecido y va a acontecer, por muy inusual que esto sea ${ }^{69}$.

Pero Santo Tomás no llega tan lejos. En la determinación no existe un encadenamiento axiomático entre las normas de justicia natural y las normas del derecho civil o positivo, de manera que, como enseña Finnis, no debe buscarse una razón para todo lo establecido por la ley humana, porque, de hecho, no siempre existe una razón para que el contenido de una ley sea $\mathrm{X}$ en vez de $\mathrm{Y}^{70}$.

Dado lo expuesto, las normas obtenidas por vía de determinación, se derivan, no por consideraciones especulativas acerca de lo bueno o lo malo moral, sino por medio de razonamientos prácticos que toman en cuenta las distintas circunstancias en las que se realiza la acción. Luego, en la determinación no se trata de conocer un único modo de actuar

67 Cf. J. Finnis, Natural Law and Natural Rights, 284 ss.

68

Cf. TomÁs de Aquino, Summa Theologiae, I-II, q. 95, a. 2.

69 Cf. J. Finnis, The Truth in Legal Positivism, 177.

70 Cf. J. Finnis, The Truth in Legal Positivism, 177. 
que sea correcto, sino de decidir un modo de obrar adecuado para la comunidad de que se trate, esto es, de elegir uno entre los muchos medios disponibles para lograr un mismo fin. Ahora bien, porque una consecuencia necesaria de la ley natural, por muy lejana que se encuentre de sus principios más generales, pertenece a la ley natural ${ }^{71}$, las leyes del derecho positivo no pueden derivarse de esos principios de justicia por vía de conclusión, ya que en estas siempre existe un elemento creativo por parte de la autoridad política. Por esta causa, además de las normas deducidas desde la ley natural por vía de conclusión, que traducen más o menos inmediatamente esos preceptos de justicia ${ }^{72}$, deben darse una serie de reglas concretas que cubran todos esos casos de la vida social en donde la tarea del legislador no consiste en una traslación tan directa del derecho natural al sistema jurídico ${ }^{73}$.

Esto solo puede tener lugar si aceptamos la posibilidad de un agregado de normatividad que no puede ser reducido a una tarea lógico-deductiva por parte del legislador, tal como se muestra en el siguiente ejemplo: ante un problema ambiental concreto, el derecho natural podría exigir que se adoptase alguna medida para solucionarlo, pero sin prescribir ningún modelo en particular entre las diversas posibilidades razonables para tratar el asunto ${ }^{74}$. Elegida la alternativa que se considere más adecuada, el derecho natural tampoco dictará una única solución correcta si, por ejemplo, se tuviera que realizar una elección entre tolerar un determinado grado de contaminación ambiental y sacrificar una medida determinada de desarrollo económico, u otro tipo de compromiso prudencial. "En aquellos casos en que se debe llegar a este tipo de medidas prudenciales, la justicia natural exige únicamente que las decisiones se adopten mediante procedimientos que tengan adecuadamente en cuenta los derechos e intereses de todas las partes afectadas" 75 . Lo anterior

71 Cf. Tomás de Aquino, In Ethicorum, V, lect. 12, n. 1023.

72 Cf. R. George, Il diritto naturale nell'età del pluralismo (Lindau, Turín, 2011), 89 ss.

73 Cf. R. George, Entre el derecho y la moral, 79.

74 Cf. R. George, Entre el derecho y la moral, 81.

75 R. George, Entre el derecho y la moral, 81. De la misma manera, escribe George: "entender el principio práctico básico que identifica la salud como un bien [...] y la preservación de la salud humana como una meta importante es una operación fácil. Partiendo de esto, un legislador moderno podrá ver sin dificultad, por ejemplo, la necesidad de idear un sistema de regulación de la circulación de vehículos como forma de proteger la salud y la seguridad de los conductores y los peatones. En este 
quiere decir que la ley positiva no se encuentra en una relación directa e inmediata con los principios naturales, que son su fundamento. Por eso puede afirmarse que, prima facie, no existe una conexión necesaria o conceptual entre la ley positiva y los principios morales ${ }^{76}$ : una norma jurídica como está prohibido ir a más de $60 \mathrm{~km} / \mathrm{h}$ no se encuentra exigida por la moral mientras no sea válidamente establecida por la autoridad del Estado.

Pero esto no significa que no exista ningún tipo de vinculación entre los principios morales y el derecho de ley: precisamente porque se trata de normas derivadas, las razones que tiene la autoridad para establecer sistemas de derecho positivo incluyen razones morales ${ }^{77}$, y solo en la medida que las determinaciones incluyan aspectos de derecho natural pueden ser consideradas como fuentes de justicia. En caso contrario, no serán verdaderas determinaciones, sino corruptio legis, como escribe Santo Tomás ${ }^{78}$.

Todo lo dicho nos permite sostener que las normas positivas son, en alguna medida, objetos culturales ${ }^{79}$, esto es, construcciones autoritativas del legislador que disponen sobre lo justo para una ciudad particular ${ }^{80}$. Se trata, en este sentido, de normas cuya juridicidad es extrínseca o accidental $^{81}$, porque la raíz de su racionalidad no procede inmediatamente de lo justo natural, sino directamente de la autoridad legítima del Estado, "que establece como justo algo que hasta ese momento resultaba indiferente en materia de justicia" ${ }^{2}$.

aspecto, el bien común -al que el legislador debe servir y fomentar- claramente exige tal sistema, pero del derecho natural no se podrá deducir directamente un modelo perfecto de regulación del tráfico".

76 Cf. J. Finnis, The Truth in Legal Positivism, 179 ss.

77 Cf. J. Finnis, On the Incoherence of Legal Positivism, 1607 ss.

78 Cf. Tomás de Aquino, Summa Theologiae, I-II, q. 95, a. 2.

79 Cf. J. Finnis, Legal Reasoning and Practical Reason, en su Reason in Action (Oxford University Press, Nueva York, 2011), 219-220.

80 Cf. Tomás de Aquino, In Ethicorum, V, lect. 12, n. 1021.

81 Cf. C. Massini, Filosofía del derecho. La justicia (Abeledo-Perrot, Buenos Aires, 2005), 42.

82 C. Massini, La ley natural y su interpretación contemporánea (Eunsa, Pamplona, 2006), 171. 
En definitiva, señala Santo Tomás que por su carácter derivado, la ley positiva contiene el derecho natural, mas no lo instituye ${ }^{83}$, "ya que este no toma fuerza de la ley, sino de la naturaleza; pero la escritura de la ley contiene e instituye el derecho positivo, dándole la fuerza de autoridad" $"$. Con todo, así como la ley positiva no da fuerza al derecho natural, tampoco puede restársela o disminuírsela, ya que la voluntad de los hombres no puede convertir en lícito aquello que es directamente contrario a los bienes básicos o a los principios morales.

3. La DETERMinACión DEL DERECHO NATURAL EN SENTENTIA LibRI ETHICORUM

En sus Comentarios a la Ética, compuestos, posiblemente, hacia 12711272, enseña Santo Tomás que "lo justo legal o positivo ${ }^{85}$ tiene siempre su origen en el derecho natural, tal como lo dice Tulio en su Retórica" ${ }^{\text {" }}$. La misma idea (y referencia a Cicerón) se repite en el Comentario a las Sentencias ${ }^{87}$ y en las Cuestiones disputadas sobre el mal ${ }^{88}$, lo que muestra la firme autoridad que concede Santo Tomás a las conclusiones del retórico romano.

Como ya se ha indicado, la forma en que lo justo positivo se origina en el derecho natural, es la que Santo Tomás reconoce como determinación ${ }^{89}$ o especificación ${ }^{90}$, y que consiste en un ejercicio de prudencia que va más allá de la simple pretensión declarativa de lo justo natural ${ }^{91}$. Ahora bien, en el pasaje en cuestión, Santo Tomás no se detiene especialmente en el problema de la modalidad de la determinación, porque esto

\footnotetext{
83 Cf. Tomás de Aquino, Summa Theologiae, II-II, q. 60, a. 5.

84 Tomás de Aquino, Summa Theologiae, II-II, q. 60, a. 5.

85 El propio Santo Tomás ha señalado que lo justo legal y lo justo positivo son dos maneras distintas de llamar a la misma realidad: el derecho que se origina en la autoridad de la ley. Cf. Tomás de Aquino, In Ethicorum, V, lect. 12, n. 1017.

86 Tomás de Aquino, In Ethicorum, V, lect. 12, n. 1023.

87 Cf. Tomás de Aquino, In Sententiarum, IV, d. 15, q. 3, a. 1.

88 Cf. Tomás de Aquino, De Malo, q. 13, a. 4.

89 Cf. Tomás de Aquino, In Ethicorum, V, lect. 12, n. 1023.

90 Cf. Tomás de Aquino, Summa Theologiae, I-II, q. 95, a. 2.

91 Cf. E. Gallego, Fundamentos para una teoría del derecho (Dykinson, Madrid, 2005), 53.
} 
lo llevaría a alejarse demasiado del texto de Aristóteles que se encuentra comentando.

Puesto que ya se ha analizado la manera en que las normas positivas se derivan desde los principios del derecho natural, a continuación pasaremos al estudio de una de las principales afirmaciones que hace Santo Tomás en sus lecciones sobre la Ética, y que son especialmente relevantes para la defensa del estatuto y necesidad de lo justo civil o positivo: una vez que el legislador ha completado los requerimientos indeterminados de la ley natural, ya no es indiferente que esto sea de tal o cual modo. Hacer eso es justo y omitirlo es injusto ${ }^{92}$.

Antes bien, es preciso señalar que el tipo de cosas justas legales a las que se refiere Santo Tomás en este pasaje puede revestir formas muy diferentes. "A veces se trata de una ley, ya sea general o particular, mientras otras se refiere a una sentencia dada por un juez para resolver un caso" ${ }^{3}$. También pueden ser privilegios o normas concretas ${ }^{94}$. Lo importante, en todo caso, es que, en cada una de estas situaciones, la autoridad del Estado dispone como de justicia una conducta que originalmente no había sido regulada por lo justo natural, y que, por el hecho de ser establecida, se convierte en obligatoria para todos.

A este respecto, Santo Tomás recuerda el ejemplo aristotélico de los sacrificios a Brasidas ${ }^{95}$. Aunque es útil para ilustrar la idea de que los gobernantes no siempre dan disposiciones generales sino también, hasta el día de hoy, normas particulares, "tiene problemas desde el punto de vista teológico, al determinar que a un ser humano se le tributen honras divinas" 96 . Pese a esto, el ejemplo permite a Santo Tomás reconocer que aun cuando, en principio, todas las determinaciones tienen su origen en el derecho natural, hay situaciones en que esa conexión no se da realmente, sino que es el fruto de algún error ${ }^{97}$. Y, en este sentido, escribe:

92 Cf. Tomás de Aquino, In Ethicorum, V, lect. 12, n. 1020.

93 J. García-Huidobro, La recepción de la doctrina aristotélica sobre el derecho natural en el Comentario de la Ética a Nicómaco de Santo Tomás de Aquino, 237.

94 Cf. Tomás de Aquino, In Ethicorum, V, lect. 12, n. 1021.

95 Cf. Tomás de Aquino, In Ethicorum, V, lect. 12, n. 1021.

96 J. García-Huidobro, La recepción de la doctrina aristotélica sobre el derecho natural en el Comentario de la Ética a Nicómaco de Santo Tomás de Aquino, 237.

97 Cf. J. García-Huidobro, La recepción de la doctrina aristotélica sobre el derecho natural en el Comentario de la Ética a Nicómaco de Santo Tomás de Aquino, 237. 
"pertenece a lo justo natural que al bienhechor se le rindan honores, pero que a un hombre se le tributen honores divinos - tal es el caso de esos sacrificios- esto proviene del error humano"98.

Paralelamente, en la Summa, propone Santo Tomás el caso de los germanos, que, según dice, no consideraban ilícito el robo ${ }^{99}$. Sobre este asunto, afirma:

se debe concluir que la ley natural, en cuanto a los primeros principios universales, es la misma para todos los hombres, tanto en el contenido como en el grado de conocimiento. Pero en cuanto a ciertos preceptos particulares, que son como conclusiones derivadas de los principios universales, también es la misma [...] en la mayor parte de los casos; pero pueden ocurrir algunas excepciones, ya sea en cuanto a la justicia de lo determinado, a causa de algún impedimento especial (como también en algunos casos faltan las causas naturales debido a un impedimento); ya sea en cuanto al grado de conocimiento, debido a que algunos tienen la razón obscurecida por una pasión, por una mala costumbre o por una torcida disposición natural. Y así cuenta Julio César en su De Bello Gallico que entre los germanos no se consideraba ilícito el robo a pesar de que es expresamente contrario a la ley natural ${ }^{100}$.

Ambos ejemplos son una muestra del grado de mutación que puede sufrir lo justo por naturaleza al momento de ser concretado por la autoridad de la república. Sin embargo, son también una prueba de esa necesidad de atender al éthos histórico al momento de dar vida a las normas del derecho legal: no se trata de justificar una u otra costumbre, pero lo cierto es que en ambos casos pareciera darse un fundamento natural para esa determinación: mientras que en el ejemplo de Brasidas parecía natural rendirle culto a una mujer que traía muchos beneficios a la comunidad ${ }^{101}$, en el caso de los germanos, el saqueo producto de la guerra era un objetivo natural de acuerdo con sus tradiciones más ancestrales.

\footnotetext{
Tomás de Aquino, In Ethicorum, V, lect. 12, n. 1024.

99 Cf. Tomás de Aquino, Summa Theologiae, I-II, q. 94, a. 4.

100 Tomás de Aquino, Summa Theologiae, I-II, q. 94, a. 4.

101 En sus Comentarios a la Ética, Santo Tomás habla de una mujer cuando trata del sacrificio de Brasidas, pero Aristóteles se está refiriendo, en estricto sentido, a un general. Esto, en todo caso, no cambia la naturaleza del ejemplo.
} 
Pasamos ahora a la revisión del problema que nos hemos propuesto en esta sección: la fuerza del derecho positivo para instituir contenidos de justicia originariamente inexistentes en el derecho natural. Sostiene Santo Tomás que, a diferencia de lo que ocurre con lo justo por naturaleza, que "en todas partes tiene el mismo poder y fuerza para inducir al bien y apartar del mal"102, lo justo positivo solo tiene validez dentro de las fronteras de la ciudad en que se ha determinado ${ }^{103}$. Por eso sus disposiciones son variables y "no implican un concepto absoluto de cosa debida o no debida" 104 , aunque sí son obligatorias para los ciudadanos, porque lo justo, en este caso, consiste en cumplir con la determinación establecida por la autoridad ${ }^{105}$.

Esto nos hace pensar que Luis de León, uno de los comentaristas escolásticos de Santo Tomás, tiene razón cuando señala que todo lo que manda la ley positiva, una vez mandado, pertenece a la ley natural ${ }^{106}$, al menos indirectamente. Esto se debe a que, si la ley natural es el fundamento de la justicia de las determinaciones, y, como enseña Santo Tomás, lo justo, una vez establecida la ley, es cumplir con esa determinación, el deber de obedecer las normas positivas pertenece también a ley natural: primero, porque una vez mandado, el contenido de la ley humana tiene condición de justo y bueno, necesario para conservar la virtud ${ }^{107}$; "segundo, porque la ley natural, nacida de la inclinación natural que tiene el hombre a la vida civil y política, manda que el hombre

102 Tomás de Aquino, In Ethicorum, V, lect. 12, n. 1018.

103 Cf. Tomás de Aquino, In Ethicorum, V, lect. 12, n. 1018. Es importante notar que, como escribe el iusfilósofo argentino Carlos-Ignacio Massini, uno de los principales aportes de la reflexión tomista sobre el derecho natural en estos comentarios, radica en la posibilidad de precisar ciertas relaciones entre la justicia legal y la justicia natural que no habían sido tematizadas por el Estagirita. Porque, "ateniéndose literalmente al texto de la Ética Nicomaquea, pareciera que, para Aristóteles, una norma jurídica positiva puede tener valor en cuanto tal aunque resulte contradictoria con un principio de justicia natural”. C. MAssini, Filosofía del derecho. La justicia, 69-70.

104 Tomás de Aquino, Summa Theologiae, I-II, q. 104, a. 1.

105 Cf. Tomás de Aquino, In Ethicorum, V, lect. 12, n. 1020.

106 Cf. Luis de León, De Legibus, q. 5, a. 3.

107 Cf. Luis de León, De Legibus, q. 5, a. 3. 
obedezca al Estado o al que lo representa, ya que sin esta obediencia no puede durar la vida en sociedad" ${ }^{108}$.

De alguna manera, entonces, la misma ley positiva puede llamarse de ley natural: en cuanto que la justicia del primer principio práctico permanece en el resto de preceptos derivados ${ }^{109}$. Es decir, en la medida en que pertenece a la naturaleza de la razón "avanzar gradualmente de lo imperfecto a lo perfecto" 110 , desarrollando reglas de la acción más particulares, pero que se enraízan en la justicia de los primeros principios del obrar.

A esto alude Santo Tomás cuando anota que la ley natural puede modificarse por adición, "en la medida en que incorpora disposiciones que se consideran útiles para la vida humana, procedentes tanto de la ley divina como [...] de las leyes humanas"111. Y así, escribe: "hay muchas acciones virtuosas que no responden de manera inmediata a una inclinación natural, sino que son el resultado del proceso racional por el que los hombres buscan lo más útil para vivir" ${ }^{\prime 12}$.

Dado lo expuesto, cualquiera ley humana, justa, por cierto, debe tenerse como obligatoria y de ley natural, en tal forma que su incumplimiento daría lugar a una injusticia. La razón de esto radica en que, como dice Santo Tomás, "la ley escrita contiene el derecho natural"113, de manera que "siempre que el ciudadano usa el derecho positivo, hace uso también del derecho natural"114, que se encuentra contenido en las leyes del Estado.

Si el incumplimiento de las determinaciones (justas) supone, a la vez, el incumplimiento de las normas naturales, la inobservancia de la ley humana que establece, por ejemplo, las formalidades de un matrimonio, traería como consecuencia la nulidad jurídica de ese contrato, aunque las partes hayan pactado de buena fe y con plena libertad y conciencia del asunto.

108 Luis de LeÓn, De Legibus, q. 5, a. 3. Esta obligación de obediencia de las leyes positivas, no se puede entender como el deber absoluto de obediencia propuesto por el positivismo jurídico. Este consiste en una obligación que, incluso, debe cumplirse frente al derecho injusto, como observa Hart.

109 Cf. L. Elders, Autour de Saint Thomas d'Aquin (Tabor, París-Bélgica, 1987), 200 ss.

110 Tomás de Aquino, Summa Theologiae, I-II, q. 97, a. 1.

111 A. González, Claves de ley natural (Rialp, Madrid, 2006), 57.

112 Tomás de Aquino, Summa Theologiae, I-II, q. 94, a. 3.

113 Tomás de Aquino, Summa Theologiae, II-II, q. 60, a. 5.

114 A. GonzÁlez, Claves de ley natural, 155-156. 
Esta idea nos parece la más acertada. Hay quienes, sin embargo, defienden la posición contraria: que, existiendo buena fe, prima facie, dicho contrato tendría validez, aun no cumpliéndose las leyes de la república. Pero esta afirmación causa el problema de convertir al derecho humano en un ordenamiento de justicia trivial e irrelevante, y que, en el fondo, no obliga en conciencia a los ciudadanos. Si bien podría darse una situación en donde el contrato, luego de un proceso judicial, fuera considerado como efectivamente vinculante, no nos parece que la regla general sea la de restar autoridad normativa al derecho positivo: ese tipo de casos deben resolverse según la equidad ${ }^{115}$, porque hay cosas que se deben juzgar fuera de las reglas comunes del derecho ${ }^{116}$.

Puede suceder, de esta forma, que la ley "esté bien dada en general, pero que falle en un caso particular [...] sobre todo cuando el cumplimiento de la ley por razón de las circunstancias particulares no solo no favorece al bien común, sino que resulta perniciosa"117. Esto se debe, no a la falta de rectitud o injusticia de las leyes, sino a su radical imperfección para prever correctamente todos los casos que registra la vida

115 Cf. Tomás de Aquino, In Ethicorum, V, lect. 16, n. 1083. Y así, señala Santo Tomás: "al ser infinitos los casos particulares, no pueden ser todos ellos abarcados por el intelecto humano, de tal manera que la ley se aplique a cada caso en particular [...] Pero es evidente que nuestro intelecto puede decir algo verdadero sobre algunos casos en universal, como sucede con lo necesario, en lo que no puede ocurrir defecto. Pero, de otros, no es posible decir algo verdadero en universal, como sucede con lo contingente, en lo cual, aunque algo sea verdadero en la mayoría de los casos, en unos pocos no obstante falla". Esto no quiere decir que la ley humana pierda su rectitud: "aunque en algunos casos haya una falla proveniente de la observancia de la ley, sin embargo, la ley es recta. Pues esa falla no proviene de parte de la ley que fue razonablemente dada, ni proviene de parte del legislador que habló según la condición de la materia, sino que es una falla que proviene de la naturaleza de las cosas. Pues tal es la materia de las acciones humanas, que no se da universalmente del mismo modo, sino que en algunos pocos casos se diversifica”. ToMÁs DE Aquino, In Ethicorum, V, lect. 16, nn. 1083-1085.

116 Cf. Tomás de Aquino, Summa Theologiae, II-II, q. 51, a. 4. Ahora bien, como indica Santo Tomás, "la epiqueya no descuida la justicia sin más, sino lo justo establecido en una ley particular. Tampoco se opone a la severidad que surge cuando es pertinente el cumplimiento de la ley. Pero es vicioso ser esclavo de la ley cuando esto no procede". Tomás de Aquino, Summa Theologiae, II-II, q. 120, a. 1.

117 Luis de León, De Legibus, q. 7, a. 5. 
jurídica y social ${ }^{118}$. En este sentido, aunque el deber de obedecer las leyes del Estado pueda ser matizado, por ejemplo, con la institución de la equidad, "normalmente hay que partir del supuesto de que cada ley debe obedecerse a la letra. No le toca a la ley demostrar que es sólida y aplicable, sino que le incumbe a la persona que está dudando demostrar que no es preciso obedecer la ley" ${ }^{\prime 19}$.

Ahora bien, el problema de nuestra interpretación radica en el hecho de que Santo Tomás parece inclinarse por la segunda de las posibles lecturas, aquella que sostiene que, en presencia de buena fe, el contrato debe considerarse como jurídicamente existente. Así, señala el de Aquino en sus comentarios al Liber Sententiarum que, si una pareja contrae matrimonio antes de la pubertad y tienen relaciones mientras son aún legalmente menores de edad (aunque físicamente maduros), su matrimonio es válido, aun cuando exista una norma acerca de la edad mínima para contraer ${ }^{120}$.

Pero el pasaje aducido, tomado, como se ha dicho, de sus Comentarios a las Sentencias, es anterior al Tratado de la Ley, que es donde Santo Tomás defiende el carácter obligatorio de las leyes del derecho positivo: "las leyes dadas por el hombre, o son justas, o son injustas. En el primer caso tienen poder de obligar en conciencia en virtud de la Ley Eterna, de la que se derivan, según aquello de Proverbios $8,15^{\prime 121}$. Luego, las leyes del derecho humano siempre obligan a su cumplimiento. Decidir en contra de aquellas no solo es una injusticia contra la autoridad del Estado; también es una injusticia contra el derecho natural ${ }^{122}$, porque, como escribe Santo Tomás, la acción justa se da solamente cuando se hace lo que es justo naturalmente y lo que es justo según la ley ${ }^{123}$.

118 Cf. C. Massini, Sobre el realismo jurídico (Abeledo-Perrot, Buenos Aires, 1978), 85. En este sentido, es importante recordar las enseñanzas de Platón, quien escribe: "una ley no podrá nunca abarcar a un tiempo con exactitud lo ideal y más justo para todos y luego dictar la más útil de las normas; porque las semejanzas entre los hombres y los actos y el hecho de que nada goza jamás, por así decirlo, de fijeza entre las cosas humanas, no permiten que ningún arte, sea el que sea, imponga algún principio absoluto valedero para todas las cosas y para todo tiempo". Platón, Politicus, 294b.

119 G. Grisez y R. Shaw, La vida realizada en Cristo (Palabra, Madrid, 2009), 143.

120 Cf. Tomás de Aquino, In Sententiarum, IV, d. 36, a. 5.

121 Tomás de Aquino, Summa Theologiae, I-II, q. 96, a. 4.

122 Cf. Tomás de Aquino, Summa Theologiae, II-II, q. 60, a. 5.

123 Cf. Tomás de Aquino, In Ethicorum, V, lect. 12, n. 1033. 
La derivación del derecho positivo desde el derecho natural en Tomás de Aquino | 701

\section{Consideraciones finales}

Al cierre de esta exposición sobre la doctrina tomista de la determinación del derecho natural, nos ha parecido adecuado presentar las siguientes conclusiones:

i. Entre las ideas que defiende el iuspositivismo se encuentra la existencia de un ordenamiento de justicia sin lagunas, lógicamente completo, y que tiene respuestas para todos los casos jurídicos. La exposición tomista del derecho natural, por el contrario, acepta "el inevitable vacío de regulación que se produce con frecuencia en todo sistema jurídico concreto y real" 124 , que pone en evidencia que el derecho es un fenómeno parcialmente incompleto, y que está llamado a concretarse por la discrecionalidad de los gobernantes.

ii. El derecho exhibe un inevitable espacio de indeterminación. Tal espacio de indiferencia es deseable y necesario, dada la contingencia de la vida humana. No nos referimos, solamente, a la indefinición lingüística que pueda darse en las leyes del Estado, o a la vaguedad que se puede presentar en el sistema de derecho positivo. También el derecho natural está afecto a una forma de indeterminación o generalidad tal que debe ser subsanada, de acuerdo con los intereses sociales, por la prudencia de la autoridad.

iii. Esta indeterminación (o indiferencia) no equivale, en todo caso, a falta de objetividad, puesto que los preceptos de la razón natural existen como puntos de referencia normativos dotados de una objetividad en sentido fuerte ${ }^{125}$, de modo tal que sus disposiciones son el verdadero fundamento del razonamiento moral y judicial ${ }^{126}$.

124 F. Puy, "Iusnaturalismo y iuspositivismo", en J. Ramos Pascua y M. Rodilla (eds.), El positivismo jurídico a examen (Eusal, Salamanca, 2006), 949.

125 Cf. C. Massini, "La objetividad en la interpretación jurídica. La objetividad jurídica modesta y sus problemas", en J. Etcheverry y P. Serna (eds.), El caballo de Troya del positivismo jurídico. Estudios críticos sobre el Inclusive Legal Positivism (Comares, Granada, 2010), 119 ss.

126 Es solo a partir de una objetividad de este tipo que resulta posible fundamentar, de modo suficiente, las realidades prácticas y los absolutos morales que defiende la doctrina del derecho natural. Cf. C. MAssini, El derecho natural y sus dimensiones actuales (Ábaco de Rodolfo Depalma, Buenos Aires, 1998), 125. 
En este sentido, para la doctrina de la determinación, los principios naturales representan proposiciones normativas de carácter objetivo e incondicionado. No obstante, que sean proposiciones objetivas, en el sentido de independientes de las valoraciones humanas, no significa que sean verdaderamente suficientes para la coordinación de la vida social, porque solo hacen referencia a unas pocas verdades morales de carácter universal: que no se puede matar directamente a un inocente, que el adulterio es siempre una injusticia, que el robo es intrínsecamente malo, que nunca puede justificarse la mentira, y el resto de especies de estos géneros de acción.

iv. Allí donde se requiere de una ley positiva para resolver un problema de coordinación, a menudo ocurre que aparecen como razonables un sinnúmero de posibles soluciones, todas ellas con inconmensurables ventajas y desventajas ciertas ${ }^{127}$. En este caso, la elección de la alternativa más adecuada es un problema de prudencia y de voluntad por parte del legislador.

v. Los principios naturales "son solamente un fragmento de la moralidad. Son solamente la manifestación de los principios básicos de la moral"128. Suministran un conocimiento necesario e inmutable, sin duda imprescindible para nuestra vida, pero sumamente general si se compara con el carácter concreto de la acción ${ }^{129}$.

127 Cf. R. George, Kelsen y Santo Tomás sobre «la doctrina de la ley natural», 83.

128 J. Finnis, "Aristóteles, Santo Tomás y los absolutos morales", en A. García Marqués y J. García-Huidobro (eds.), Razón y praxis (Edeval, Valparaíso, 1994), 334.

129 Cf. L. Palacios, La prudencia politica (Gredos, Madrid, 1978), 24-26. Tal indeterminación de los principios morales puede verse, en opinión de Palacios, en el análisis de la temperancia: cuando las normas naturales mandan que el hombre sea temperante, no nos dicen cuántas y cuáles acciones debe realizar para alcanzar la virtud. Tampoco cuáles son los medios para conseguir esa disposición. Por eso, escribe el autor, "para ser temperante no me basta con el mandamiento de la sindéresis, diciéndome desde su altura que debo sujetar y medir mis pasiones concupiscibles, ni tampoco un bello estudio sobre la naturaleza de la templanza, tejido por los razonamientos de la ciencia moral; es menester que conozca, además, las condiciones íntimas en que se desenvuelve mi apetito concupiscible, las repercusiones que en él produce el bien deleitable, mi estado, mi salud en aquel momento, las relaciones con mis semejantes, mis experiencias del pasado, etc., y solamente a la vista de estas circunstancias podré saber cuál es la acción que debo poner aquí y ahora”. 
La derivación del derecho positivo desde el derecho natural en Tomás de Aquino | 703

Los principios naturales no nos dicen, en este sentido, qué debemos hacer, sino que nos indican solamente lo que es básico para cualquier acción ${ }^{130}$. La necesidad de ulteriores determinaciones de estos preceptos, "según se toman en cuenta las circunstancias que inevitablemente han de modificarlos en su aplicación al caso singular, muestra que ellos no pueden dar razón completa del bien de la operación moral concreta"131. Es por eso que Santo Tomás señala que "aunque exista necesidad en los principios más generales, cuanto más descendemos a lo particular, tanto más defectos encontramos"132; de ahí que la verdad o rectitud de los preceptos de la ley natural no sea la misma en todos los hombres considerada en concreto, sino solo en general ${ }^{133}$.

vi. En la vida diaria, cuando se trata de tomar decisiones, resulta de muy poca o ninguna ayuda el decir: hay que hacer el bien o hay que actuar según la recta razón. Todos queremos obrar bien y ser racionales, pero nuestro problema es determinar qué significa ser razonable aquí y ahora ${ }^{134}$. En este sentido, la exigencia de unos preceptos de la acción más particulares surge por la naturaleza misma de la práxis: máximamente determinada y contingente. Tales preceptos se obtienen a partir de un procedimiento hermenéutico que se entiende, solamente, si reconocemos el carácter objetivo y fundamental de los principios de la ley natural, como su condición de infra-determinados y generales.

vii. Tal generalidad de los principios naturales se debe entender en los siguientes términos: como enseña John Finnis, la estrategia central de la doctrina de la determinación consiste en la infra-determinación (y no en la pura indeterminación) de la mayoría, si no de todas, las exigencias prácticas de la razón en el campo de la acción humana ${ }^{135}$. Lo anterior

130 Cf. G. Grisez y R. Shaw, La vida realizada en Cristo, 91.

131 J. Widow, "Ley natural y conciencia", en M. Ayuso (ed.), Dalla geometria legale-statualistica alla riscoperta del diritto e della política (Marcial Pons, MadridBarcelona, 2006), 412.

132 Tomás de Aquino, Summa Theologiae, I-II, q. 94, a. 4.

133 Cf. Tomás de Aquino, Summa Theologiae, I-II, q. 94, a. 4.

134 Cf. J. García-Huidobro, El acceso a la ley natural. Comentario a un texto de Aquino (S. Th. I-II, 94, 2e), 213-214.

135 Cf. J. Finnis, "Natural Law. The Classical Tradition", en J. Coleman y S. Shapiro (eds.), The Oxford Handbook of Jurisprudence and Philopsophy of Law (Oxford University Press, Oxford, 2002), 23. 
quiere decir que la ley natural no está completamente determinada, y por eso no puede afirmarse que el derecho positivo sea una simple réplica del derecho natural. Pero tampoco está totalmente indeterminada, de manera que el derecho positivo puede derivarse de sus exigencias prácticas y respetarlas ${ }^{136}$. Pese a esto, las leyes naturales son insuficientes para guiar la acción individual.

viii. Supuesta esa insuficiencia de los principios naturales, debe proponerse la existencia de un mecanismo de creación de las normas positivas que vaya más allá de la pura función deductiva. Tal procedimiento es el que llamamos determinación, y que existe, fundamentalmente, porque "muchos de los principios éticos de justicia admiten diversos modos de realización en la práctica" ${ }^{137}$; y porque es imposible para la autoridad anticiparse a todas las situaciones de la vida social que debe resolver.

ix. Este ejercicio constructivo no se opone a la existencia de una ley que es natural. En la tradición escolástico-salmantina, no es posible separar lo que es natural del artificio, sobre todo en la medida que aquello que representa una creación humana o cultural (como la ley positiva) no es más que una extensión de lo que es secundum naturam ${ }^{138}$. El arte imita la naturaleza. Eso es lo que se encuentra en el fondo del problema de la determinación.

$\mathrm{x}$. Lo esencial de la derivatio per modum determinationis radica en que la ley natural no especifica cuál es la solución más adecuada para cada uno de los problemas sociales que deben ser enfrentados por la autoridad política. El legislador no está obligado a tomar una decisión en un sentido determinado al momento de dar vida a las normas del derecho positivo. Solo debe tomar una decisión que excluya otras alternativas posibles.

xi. El resultado de este proceso constructivo de las normas positivas, es el que da origen a lo justo en relación a una república determinada, y que obliga en conciencia por la pura voluntad de los hombres. Las normas de esta clase de justicia podrán añadir "algo (en realidad, mucho) a

136 Cf. C. Pereira, La autoridad del derecho. Un diálogo con John M. Finnis (Comares, Granada, 2008), 186.

137 A. Rodríguez Luño, Ética general (Eunsa, Pamplona, 20065), 263.

138 Cf. A. Gehlen, Prospettive antropologiche (Il Mulino, Bolonia, 1987), 32. 
las directrices generales de la moral"139, añadido que será específico para cada comunidad, según el tiempo y lugar de que se trate ${ }^{140}$.

xii. Las leyes positivas, "que son como conclusiones de los principios naturales" ${ }^{141}$, entregan concreción y aplicabilidad a los preceptos de la recta razón, y son tan necesarias para la vida social y política, que, sin ellas, los principios naturales no podrían cumplirse con facilidad. Según esto, se refuerza la enseñanza de los doctores escolásticos, para los cuales, las leyes humanas no son únicamente útiles para conseguir el orden social, sino necesarias para el logro de la paz y la seguridad pública.

xiii. Finalmente, en la medida que se crean contenidos de justicia inexistentes por derecho natural, se va configurando el ámbito de los mala quia prohibita. En esta zona del sistema jurídico, el derecho promulgado (o positivo) intenta promover el bien común prohibiendo o exigiendo cierta clase de acciones cuya moralidad no había sido definida ex ante. En concreto, lo que hace la autoridad es ordenar nuevas razones para la acción, que, a pesar de que se fundan en el derecho natural, no existían sino hasta después de su determinación por parte del poder del Estado $^{142}$.

139 J. Finnis, On the Incoherence of Legal Positivism, 1604.

140 Cf. J. Finnis, On the Incoherence of Legal Positivism, 1604.

141 Pedro de Aragón, De Justitia et Jure, q. 85, a. 1.

142 Sobre este asunto: Cf. J. Finnis, "Sobre los caminos de Hart: el derecho como razón y como hecho", en M. Kramer, C. Grant, B. Colburn y A. Hatzistavrou (comps.), El legado de H.L.A. Hart. Filosofía jurídica, política y moral (Marcial Pons, Madrid-Barcelona-Buenos Aires, 2012), 43-44. 
Resumen: Un principio básico de la filosofía del derecho de Santo Tomás es el que postula que todas las leyes positivas, cuando son racionales, se derivan de la ley natural. El derecho natural es el principio normativo del cual las reglas de la justicia humana toman su fuerza obligatoria. A esta manera de derivarse lo justo positivo desde la ley natural se le conoce como derivación por determinación. Es este el problema que nos hemos propuesto tratar con el siguiente trabajo. Para esto, nos concentraremos en dos de los pasajes de la obra tomista: la q. 95 a. 2 de la I-II y los comentarios al libro V de la Ética de Aristóteles.

Palabras clave: Determinación del derecho natural, Santo Tomás, derivatio per modum determinationis, derecho positivo, iusnaturalismo clásico.

Abstract: A basic principle of Aquinas' philosophy of law postulates that all positive laws, the rational human laws, are derived from natural law. The natural just is the normative principle that makes obligatory to human laws. This form of derivation of positive law from natural law is known as determinatio. We wanted to address this issue with the next paper. For this, we focus on two of the passages of the work of Aquinas: the q. 95 a. 2 of the I-II and the comments to the Vth book of Aristotle's Ethics.

Keywords: Determination of natural law, Aquinas, derivatio per modum determinationis, positive law, classical iusnaturalism. 